\title{
Cesarianas e saúde pública: uma imbricação necessária
}

\section{C-sections and public health: a necessary entanglement}

Rio de Janeiro, 20 de fevereiro de 2018.

O artigo de nossa autoria analisa o capítulo "Cesariana" do livro-texto do renomado obstetra brasileiro Jorge de Rezende, por reconhecê-lo como importante referência no campo da obstetrícia brasileira - ponto sobre o qual não divergimos de Raphael Parente. Na conclusão de nosso texto, mencionamos um artigo de opinião por ele produzido que apresenta uma crítica às taxas de cesariana ideais estabelecidas pela OMS. Em sua carta, nosso interlocutor questiona a crítica relacionada ao seu artigo de opinião veiculado em um jornal diário de circulação nacional. E é sobre esse item que nos ateremos neste espaço de resposta.

Ao nos referimos ao artigo de Raphael Parente, tivemos a finalidade de contextualizar a permanência das ideias difundidas por Rezende em sua obra. Não tivemos a pretensão de entrar nas controvérsias sobre as taxas de cesariana aceitáveis, mas sim demonstrar que os argumentos utilizados pelo doutor Parente e seus colaboradores corroboram a análise de que as ideias propagadas no livro de Rezende - e principalmente o estilo de pensamento médicoobstétrico que ele contribuiu para formar - são atuais e alcançam os, ainda presentes, desafios da assistência obstétrica. Compartilhamos a mesma ideia de que a questão dos desfechos da atenção obstétrica não se resume a um limite pré-estabelecido de taxas de cesariana. Em nossos estudos temos encontrado que uso mais ampliado da cirurgia cesariana nos partos tem colaborado para uma compreensão do procedimento como trivial, cada vez mais normal, tanto entre profissionais quanto entre mulheres (Nakano, Bonan, Teixeira, 2015, 2017).

É nesse caminho que, mais uma vez concordando com nosso interlocutor, vemos as taxas de cesariana deixarem de ser um parâmetro isolado da boa qualidade da atenção ao parto, para comportar outros quesitos que dizem respeito à segurança do parto, como o momento da decisão pela cesárea (anterior ou na vigência do trabalho de parto), a garantia de informação de qualidade às mulheres sobre as vias de parto e os riscos a elas associados, e a definição de um tempo mínimo para a finalização da gestação quando em situação eletiva (no caso, 39 semanas). Nesse sentido, falamos o mesmo conteúdo, porém de modos diferentes. O que nos diferencia de modo importante - sendo ponto principal de nossa resposta - é que entendemos as taxas de cesárea no Brasil como parte de uma complexa imbricação de fatores financeiros, corporativos, organizacionais, institucionais, culturais, entre outros.

Discordando com veemência do que nos é direcionado como crítica - ou seja, de uso maniqueísta da ciência (e dos recursos públicos que financiam as pesquisas) para privilegiar um determinado grupo profissional ou tipo de parto - reafirmamos que tivemos e temos como premissa teórica e metodológica não olhar a questão "cesárea" a partir de polarizações. Chamamos a atenção do autor que, assim como analisamos os meandros do aperfeiçoamento da técnica da cesariana - o que muito colaborou para o entendimento de sua normalidade -, estivemos atentos aos diferentes discursos em torno da cesárea. Ao vincular os melhores desfechos da assistência ao parto no setor privado, relacionando-os às taxas de cesariana, o 
autor confere centralidade absoluta ao procedimento cirúrgico em si e ignora a complexidade de questões envolvidas na qualidade da atenção obstétrica - que inclui pré-natal, parto, nascimento e puerpério -, que passa por determinantes econômicos e sociais, incluindo de modo ineludível investimentos do Estado em políticas saúde, educação, saneamento e distribuição de renda.

Por fim, como pesquisadores em saúde pública, inseridos em uma instituição cuja história é marcada pelo compromisso com o direito universal à saúde e a construção de um sistema de saúde pautado pela equidade e integralidade de suas ações, e sendo, nós mesmos, partícipes há quase duas décadas do diálogo entre a sociedade e o Estado nos esforço de desenvolver políticas na área dos direitos à saúde sexual e reprodutiva, incluindo a assistência obstétrica, divergimos inteiramente da opinião do autor quando acusa que com tais iniciativas visam "baixar taxas de cesarianas a qualquer custo como uma cortina de fumaça para gastarem menos, colocando a saúde da população em risco e como uma forma corporativista de retirar obstetras da assistência ao parto".

O que vislumbramos, e fazemos coro com nosso interlocutor, é alcançar uma melhor atenção à saúde das mulheres, mas entendemos que isso não será obtido simplesmente disponibilizando cesariana a todas; ao contrário, será alcançado quando todas as mulheres, do setor público ou do setor privado, tiverem seus direitos garantidos, com acesso a uma assistência digna, isto é, integral e de qualidade, incluindo acesso à cesariana quando ela se fizer necessária.

\section{REFERÊNCIAS}

NAKANO, Andreza Rodrigues; BONAN, Claudia; TEIXEIRA, Luiz Antônio.

O trabalho de parto do obstetra: estilo de pensamento e normalização do "parto cesáreo" entre obstetras. Physis, v.27, n.3, p.415-432. 2017.
NAKANO, Andreza Rodrigues; BONAN, Claudia; TEIXEIRA, Luiz Antônio.

A normalização da cesárea como modo de nascer: cultura material do parto em maternidades privadas no Sudeste do Brasil. Physis, v.25, n.3, p.885-904. 2015.

Andreza Rodrigues Nakano

Instituto Nacional de Saúde da Mulher, da Criança e do Adolescente Fernandes Figueira/Fiocruz.

Rio de Janeiro - RJ - Brasil

Claudia Bonan

Instituto Nacional de Saúde da Mulher, da Criança e do Adolescente Fernandes Figueira/Fiocruz. Rio de Janeiro - RJ - Brasil

Luiz Antônio Teixeira Casa de Oswaldo Cruz/Fiocruz. Rio de Janeiro - RJ - Brasil 